\title{
‘HUMAN AFTER ALL'? DAFT PUNK E O CULTO À MÁQUINA
}

\author{
Marcelo Cizaurre Guirau ${ }^{1}$ \\ Rafael Mantovani ${ }^{2}$
}

\begin{abstract}
Resumo: Daft Punk é um duo formado nos anos 1990 e consagrado na década seguinte. É considerado por muitos como inovador e os próprios componentes apresentam um discurso de experimentação em música. Seu último lançamento, Random Access memories, de 2013, foi bastante aclamado por crítica e público, tendo vencido o prêmio de melhor álbum do ano de 2013 - dentre outros quatro prêmios - no Grammy 2014. O que o Daft Punk traz de realmente inovador é que eles abolem a figura humana, efeito alcançado com a eliminação da figura de (ao menos) um frontman elou substituindo, em geral, a voz humana pela voz mecanizada. Abolindo o homem e tendo como fantasia que a produção musical é feita por máquinas, tem-se na banda representado de forma mais completa o sonho mecanicista do século XX, trazido pela primeira vez pela escola futurista.
\end{abstract}

Palavras-chave: Techno. Daft Punk. Utopia. Máquina. Ciborgue.

INTRODUÇÃO ${ }^{3}$

No dia 15 de maio de 2013, Roberto Nascimento escreveu uma crítica ${ }^{4}$ ao quarto álbum de estúdio do duo francês Daft Punk, Random access memories. Em tom extremamente elogioso, o texto destaca uma frase que um dos componentes da banda, Thomas Gangalter, disse à revista Rolling Stone: "A dance music atual está na zona de conforto. Não tem caminhado um palmo". Tal afirmação permite que se infira que a banda se pretende vanguarda. Pode-se argumentar que uma frase dita por um produtor cultural em uma entrevista pode não ser totalmente sincera e visar apenas publicidade.

\footnotetext{
${ }^{1}$ Marcelo Cizaurre Guirau possui graduação em Letras (Português / Inglês) pela Universidade de São Paulo. (2004); especialização em Estudos de museus de arte pelo Museu de Arte Contemporânea da Universidade de São Paulo -MAC-USP (2006); mestrado em Letras (Estudos Linguísticos e Literários em Inglês) pela Universidade de São Paulo (2007); especialização em Linguagens da arte pelo Centro Universitário Maria Antônia da Universidade de São Paulo (2008); doutorado em Letras (Estudos Linguísticos e Literários em Inglês) pela Universidade de São Paulo. É professor do Centro Universitário Ítalo Brasileiro. Email: cizaurre@yahoo.com

${ }^{2}$ Rafael Mantovani é doutorando (2011) em Sociologia pela Universidade de São Paulo (USP). É mestre (2009) pela PUC/SP em Ciências Sociais, com concentração na área de Antropologia, tendo sido convidado como pesquisador do Instituto Gino Germani do programa de pós-graduação da Universidad de Buenos Aires. É graduado (2005) em Ciências Sociais também pela PUC/SP. Tem experiência na área de sociologia histórica e desenvolve pesquisas nos temas de formação de Estados-nação, literatura e pintura, controle social e história da ciência. Email: mantovani@usp.br.

${ }^{3}$ Agradecemos a leitura e comentários de André Romano, que enriqueceram esse texto.

${ }^{4}$ Nascimento, Roberto. "Manifesto contra o pop impessoal", O Estado de São Paulo, 15 de maio de 2013. Conforme se observará, Roberto Nascimento se equivoca ao pensar que o Daft Punk apresentaria uma espécie de manifesto contra a impessoalidade: a impessoalidade é justamente uma das características do Daft Punk, buscada e comemorada pelo duo.
} 
Por mais que seja difícil averiguar o grau de "sinceridade" que determinada afirmação tem quando proferida por um produtor de cultura, há condições para que seja proferida e, mais do que isso, publicada. Criou-se ao redor do lançamento desse álbum uma grande expectativa. O Daft Punk é um tipo de criação social que gera legitimação simbólica em torno do que produz: o seu consumidor tem, tanto ao conhecer quanto ao apreciar, um capital simbólico específico pelo fato de a banda pertencer a um universo considerado "cult".

Por mais que não se venha aqui fazer uma discussão estritamente musical do Daft Punk, convém ressaltar que a banda não pode ser reconhecida exatamente pela inovação nos arranjos de cordas, como pretende Roberto Nascimento. Ora, por que então falar do duo formado por Thomas Bangalter e Guy-Manuel de Homem-Christo? Porque essa banda representa o sintoma mais evidente, dentro da cultura de massa, de um sonho antigo de uma parte da humanidade - que ganhou voz e expressão artística com Filippo Marinetti (1876-1944) - de que o futuro seja guiado pela suposta perfeição e racionalidade da máquina.

A música é mecanizada desde a emergência da indústria cultural. Entretanto, há algo que ainda é preservado de humano nela, algo que o Daft Punk pretende eliminar simbolicamente - o que os torna um objeto de estudo interessante para a compreensão das razões desse desprestígio do humano em face do inumano.

Trata-se de um movimento que se inicia na música pop, mais especificamente, com o Kraftwerk, banda alemã que surge na década de 1970, que produz suas músicas de forma sintética. Tratava-se da descoberta da facilidade mecânica não apenas para a gravação das músicas, mas também para a produção e criação de música por meio da máquina. A banda canta esse elogio à máquina e tem em seu repertório músicas como The robots, Autobahn e The man-machine ${ }^{5}$. Contudo, no Kraftwerk, a justaposição do humano e do tecnológico "não questiona as categorias essenciais, mas sim deve ser vista como uma mudança na aliança de uma esfera a outra" (Auner, 2003, p. 110). Posteriormente, fazer música com computadores se tornou comum e os estilos se multiplicaram em techno, synthpop, house (que, por sua vez, se divide em acid house, dirty house, progressive house, tribal house etc.), rock industrial, entre outros? Entretanto, todas essas manifestações mais importantes de cada estilo ainda conservavam um aspecto determinante: a voz humana e a figura de, ao menos, um frontman. Por mais que se faça cada vez mais música com computadores, sempre se manteve um refúgio para o humano: ao menos na voz e na figura dos artistas-criadores. Mesmo dentro do que é produzido de forma totalmente mecânica, em geral, buscou-se fugir da total mecanização: havia a preocupação de não soar mecânico demais (ao estilo

\footnotetext{
${ }^{5}$ Em inglês, o adjetivo vem, em regra, antes do substantivo. Portanto, não se trata de "homem-máquina", ou seja, um homem que tem atribuições de máquina, mas antes, "máquina-homem", ou seja, uma máquina que tem atributos humanos.

${ }^{6}$ Traduções livres dos autores no decorrer deste texto.

${ }^{7}$ Convém chamar a atenção para o fato de que não se trata aqui do desenvolvimento puramente sonoro que chegou ao techno, mas sim da evolução de uma ideia que culmina no Daft Punk. Por isso, opta-se aqui por traçar essa trajetória pelo caminho que, na música contemporânea, foi aberto pelo Kraftwerk, embora não ignoremos que alguns, como Smith (2004, p. 732), dirão que a evolução do techno francês passa pela musique concrète dos anos 1940.
} 
fundo musical de jogos de videogame) e as bandas que gravavam dessa forma demonstravam a intenção de, nas gravações, colocar algo que quebrasse a completa perfeição monótona e, nos videoclipes, criar a fantasia de que os instrumentos eram tocados por pessoas ${ }^{8}$.

Em ensaio escrito em 1927, Theodor Adorno compara o destino dos aparelhos de gravação e reprodução mecânica da voz ao da fotografia, e chega à conclusão de que a mudança da produção artesanal para a industrial transforma não apenas a forma de distribuição, mas o que é produzido. Adorno vê o processo de aperfeiçoamento da gravação de forma bastante pessimista; se de um lado as gravações ganham em volume e plasticidade, outros aspectos como a autenticidade dos sons vocais declinam, "como se o cantor fosse sendo cada vez mais distanciado do aparato" (ADORNO, 1990, p. 48).

Slavoj Zizek, comentando o ensaio de Adorno, esclarece a relação inversa entre a percepção da presença humana por trás do aparato e a perfeição da técnica de reprodução:

\begin{abstract}
Quanto mais a máquina evidencia sua presença (por meio de ruídos inoportunos, falhas de reprodução e interrupções) [ou seja, quando a perfeição da máquina se rompe], mais forte é a experiência da presença real do cantor - ou, pensando no inverso, quanto mais perfeita é a gravação, quanto mais fiel é a reprodução da voz humana pela máquina, mais humanidade é removida, mais forte é a sensação de que estamos lidando com algo "inautêntico" (ZIZEK, 2001, p. 44).
\end{abstract}

Portanto, quanto mais perfeito tecnicamente, menos aspectos humanos são percebidos; e, contrariamente, o humano é notado quando a reprodução mecânica é imperfeita (Zizek, 2001, p. 45).

Se a indústria cultural exige a perfeição técnica para veicular as músicas, nos videoclipes ao menos, as bandas geralmente ainda se preocupam em manter a imagem do homem, como se fosse ele quem estivesse tocando instrumentos que produzem determinados sons quando, em realidade, eles foram produzidos por samplers. No techno isso é comprometido, afinal, fica mais difícil imaginar que os sons comuns nesse tipo de música são produzidos por homens; mas, ainda assim, a imagem dos DJs parece ser importante, como, por exemplo, Fatboy Slim, Skazi, David Guetta, Murphy. Ou seja, por mais que a mecanização e perfeição sejam aspectos exigidos pela indústria cultural, a presença humana é mantida como lembrança da origem da obra - é ainda necessário mostrar que, por detrás de toda a tecnologia, ainda há pessoas criando. O que o Daft Punk faz é o movimento inverso: ao invés de preservar a figura humana, eles conscientemente buscam eliminá-la.

O aspecto marcante do Daft Punk está no fato de que seus integrantes se vestem de robôs. Na página da banda na internet, eles justificam essa opção estética dizendo que o fazem por não gostar da ideia do artista como "estrela" e do culto à personalidade

\footnotetext{
${ }^{8}$ Ver, como exemplos, os clipes de Kids are united, do Atari Teenage Riot, e apresentações do Prodigy, banda que faz questão de ter no palco um guitarrista e um baterista (baterista que apenas aparece nos shows, afinal, não faz parte da banda e nem grava com ela), além de diversos outros clipes de músicas cujas baterias e baixos poderiam ser feitos totalmente com samplers, mas que são tocados por pessoas: bons exemplos disso são Ministry e Nine Inch Nails.
} 
impulsionado pelo "star system": "Nós discordamos totalmente do star system e do culto à imagem física da pessoa. Nós somos músicos e essa é a única coisa de que as pessoas deveriam se lembrar" (Apud SMITH, 2004, p. 738).

Ou seja, descrevem a sua peculiaridade (a fantasia da música produzida por robôs) como se fosse uma grande crítica ou subversão ao mainstream. Assim, mascaram seu movimento de impessoalização, levado a cabo por meio da figura do robô em vez da sua própria, como crítica social.

A voz nas músicas do Daft Punk também se apresenta como imitação de robôs. Se, em determinados momentos, a banda procura aproximar a gravação de instrumentos a uma sonoridade que até parece ter sido produzida por humanos, as marcas principais de atributos humanos da cultura contemporânea (a voz e a imagem) são substituídas. A fantasia de que são robôs que fazem a música constitui uma espécie de marca específica da banda. Não fosse essa especificidade, se trataria de apenas mais uma banda que, como muitas outras, cuida com extrema disciplina do ordenamento matemático de cada nota e cada tempo para não criar estranhamento. Contudo, a forma se torna conteúdo: se as bandas, em geral, usam as possibilidades tecnológicas para exacerbar as figuras humanas (reverberação na voz, luzes que projetam sombras enormes, brilhos), no caso do Daft Punk a mecanização segue até o contato com os ouvintes e/ou a plateia: não há homens que são evidenciados pela utilização da tecnologia; é a própria tecnologia que é apresentada para ser reverenciada, afinal, se trata de dois robôs. Se não é verdadeiro que não haja homens por trás da produção da banda, é essa a fantasia que pretendem criar.

O que faz essa banda ser tão aclamada e prestigiada nos meios especializados? Talvez o que haja de subjacente ao prestígio do Daft Punk seja um antigo sonho de utopia mecanicista que se inicia no século XX. Trata-se da ideia kraftwerkiana de que eles não seriam eles "homens-máquina", mas sim uma espécie nova, máquinas com capacidade criativa: "máquinas-homem". Essa mudança de perspectiva em relação à tecnologia pode ser descrita como uma espécie de "gnosticismo tecnológico", termo de Hermínio Martins, que, para Felinto, indica

\begin{abstract}
uma mudança de perspectiva em relação às representações da tecnologia correntes até princípios do século XX. Até então, a tecnologia era representada como uma forma de extensão do corpo humano, e desse modo a imagem material do corpo tinha prioridade sobre o maquínico. No horizonte das novas tecnologias, contudo, é o humano que é absorvido pela máquina, tomando-se apenas mais um sistema de informações entre outros. O gnosticismo era uma religião dualista, depreciadora da materialidade e da corporalidade. Seu objetivo era oferecer ao adepto uma técnica espiritual capaz de permitir a liberação das amarras corporais e do espaço material. Do mesmo modo, as fantasias a respeito das novas tecnologias sonham com a superação de todos os limites físicos do ser humano, com a virtualização do corpo e a expansão da consciência (2005, p. 63).
\end{abstract}

Segundo Auner, "em nenhum aspecto das nossas vidas a penetração do humano pela máquina tem sido mais completa do que na música"” (2003, p. 99). Disso, temos

\footnotetext{
9 No original: "In no aspect of our lives has the penetration of the human by machines been more complete than in music".
} 
que o techno surge como celebração dessa penetração; e o Daft Punk como a sinalização utópica do processo levado ao ápice.

\section{O FUTURO COMO UTOPIA: A VANGUARDA FUTURISTA E O SONHO MECANICISTA}

O Daft Punk apresenta a continuação da ideologia do progresso tecnológico trazida primeiramente pelo futurismo. Para explicar os pontos de contato e as diversas diferenças entre artistas separados por um século, é importante trazer os pontos fundamentais do futurismo, embora o foco aqui seja outro. Para se chegar ao nosso objeto, é necessário entender dois pontos: 1. o comportamento iconoclasta do grupo futurista (que discrepa diametralmente com o comportamento do duo), 2. as formas de se acabar com a imagem do eu e do homem. Com relação ao primeiro ponto, as condições de produção cultural explicam o distanciamento entre o comportamento iconoclasta dos futuristas e a docilidade do Daft Punk. Com relação ao segundo ponto, mesmo atualizada, a forma de acabar com o humano na produção artística tanto dos futuristas quanto do duo apresenta técnicas e estratégias parecidas.

Perloff (1986, p. 36) já nos alertou que equacionar futurismo e fascismo é uma simplificação, afinal, entre os membros da vanguarda, havia marxistas, socialistas, anarquistas, anarco-sindicalistas. Entretanto, a ligação entre essa vanguarda artística e o movimento político ocorreu, embora muitas vezes de forma confusa e tensa (HUMPHREYS, 2001, p. 14-15). O futurismo tinha como bandeira, acima de tudo, a destruição da tradição, dos museus, bibliotecas e tudo o que representasse o passado. A violência contra a plateia era a postura de profetas do futuro que não viam outra forma de fazer arte senão destruindo o que imaginavam como passado opressivo. "A ação violenta, seja na vida, seja na arte, era encarada como o antídoto contra a letargia política, cultural e filosófica" (Humphreys, 2001, p. 9), especialmente da Itália da virada para o século XX. E o elogio da máquina, do óleo, do ritmo correto que marca o "belo" passo de veículos de rodovia e que requer a destruição acabou por cair no elogio à guerra $^{10}$, esse momento em que a grandiosidade de tudo o que é metálico, duro e espesso ganharia "poesia". Em 1909, Marinetti escreveu no seu Manifesto do futurismo: "Nós queremos a guerra - única higiene do mundo -, o militarismo, o patriotismo, o gesto destruidor dos libertários, as belas ideias pelas quais se morre [...]" (apud BERNARDINI, 1980, p. 34).

Ao menos para estes artistas, naquele momento, fazia algum sentido imaginar que os verdadeiros detentores da liberdade seriam os nacionalistas. Não é de se estranhar que grande parte dos futuristas tenha morrido no campo de batalha em nome do fascínio

\footnotetext{
${ }^{10}$ Walter Benjamin, em perspectiva oposta ao elogio da técnica dos futuristas, estabelece a relação entre automóvel e guerra: “'L'automobile c'est la guerre'. O que estava na raiz dessa surpreendente associação de palavras era a ideia de uma aceleração dos instrumentos técnicos, seus ritmos, suas fontes de energia etc., que não encontram em nossa vida pessoal nenhuma utilização completa e adequada e, no entanto, lutam por justificar-se. Na medida em que renunciam a todas as interações harmônicas, esses instrumentos se justificam pela guerra, que prova com suas devastações que a realidade social não está madura para transformar a técnica em seu órgão e que a técnica não é suficientemente forte para dominar as forças elementares da sociedade" (Benjamin, 1994, p. 61).
} 
que lhes tomou conta quando explodiram a primeira e a segunda guerras mundiais. Contudo, a ligação ao patriotismo e o elogio à guerra, apesar de serem aspectos muito consideráveis para a vanguarda, nos interessa de forma acessória. Mais importantes para nós são as técnicas para criar o assombro e tentar destruir o humano da obra.

As iniciativas para criar o esperado incômodo na plateia se iniciaram quando Marinetti assistiu à peça $U b u$ Rei, de Alfred Jarry e criou a sua própria em seguida, em 1909, chamada Roi Bombance. Era provocativa, assim como a de Jarry, e apresentava sátiras à revolução e à democracia (GOLBERG, 2006). Tratava-se da tentativa de tirar os espectadores da zona de conforto a fim de levá-los a rejeitar a tradição para, enfim, cultuar a máquina. A performance era um meio de desconcertar o público acomodado, que diversas vezes não iria entender o que estava em jogo e, portanto, "os futuristas devem ensinar todos os escritores e performers a desprezar o público, asseverava ele [Marinetti]" (GOLBERG, 2006, p. 6). Não apenas vaias, mas verdadeiros confrontos se seguiam às apresentações futuristas. Essas técnicas de Marinetti - fossem elas vender uma entrada para duas pessoas com o intuito de fazê-las brigar pelo lugar, colocar cola nos assentos, ou não ter roteiro em suas peças e incentivar o nonsense - visavam ao incômodo e ao conflito (a música ruidosa e onomatopeica que os futuristas criaram também visava à recriação do ambiente de trincheira).

Em segundo lugar, os futuristas visavam também criar uma forma de ligar os elementos em movimento para que fosse gerada a percepção da cadência mecânica. A música de ruído, mencionada acima, além de ter como intuito recriar o ambiente de trincheira, seguia, segundo o pintor Rusolo, o ritmo das máquinas. O ruído reinava "soberano sobre a sensibilidade humana" (GOLBERG, 2006, p. 11). Mas não é apenas sonoramente que se obtém a sensação de mecanicidade. No Manifesto técnico da literatura futurista de 1912, Marinetti diz que é necessário

\begin{abstract}
Substituir a psicologia do homem, já esgotada, com a obsessão lírica da matéria. Cuidado para não emprestar à matéria os sentimentos humanos, mas antes, procurar adivinhar seus diferentes impulsos diretores, suas forças de compressão, de dilatação, de coesão, e de desagregação, seus bandos de moléculas em quantidade ou seus turbilhões de elétrons. Não se trata de apresentar os dramas da matéria humanizada. É a solidez de uma chapa de aço que nos interessa por ela mesma, isto é, a aliança incompreensível e inumana de suas moléculas ou de seus elétrons, que se opõem, por exemplo, à penetração de um obus (BERNARDINI, 1980, p. 84-85).
\end{abstract}

No manifesto intitulado Declamação dinâmica e sinóptica de 1914, Marinetti explicava como deveriam ser as ações corporais baseadas na máquina. E, para acabar com a "psicologia do homem", o que o homem dissesse no palco não poderia ser expressão de sentimento, mas apenas o som mecânico: nas peças havia performers nos bastidores emitindo sons como "bulu bulu bulu" (GOLDBERG, 2006, p. 18) ou a repetição veemente da sílaba "STA" (GOLDBERG, 2006, p. 12), que, junto com outras técnicas, visavam à fusão entre atores e cenografia para a apresentação da máquina, das qualidades da máquina. No manifesto da Dança futurista, escrito em 1917, Marinetti 
deixa bastante claro qual era o desejo dos futuristas: "aquele corpo ideal e múltiplo do motor, com o qual sonhamos há tanto tempo" "(GOLDBERG, 2006, p. 14).

\section{AS QUALIDADES HUMANAS COMO INSTRUMENTOS DA MÁQUINA}

Passado quase um século, o homem civilizado se vê rodeado de aparelhos, números, estatísticas, introjeção passiva de chips no seu cotidiano: a aceitação da máquina já não é uma batalha. Estando bem estabelecido que o progresso tecnológico facilita a vida do homem por meio da máquina, a disposição de tirar o homem da arte já não demanda tanta agressão à plateia; é certo que tal gosto ainda pode trazer certo espanto, mas em geral não passa da ideia de "cult", um diferencial criativo. Não só não é necessário incomodar a plateia como, aos que pretendem fazer parte da indústria cultural, não é requisitado assombrar os espectadores. Além do mais, há uma série de temas nas músicas do Daft Punk que não estavam dados à época do futurismo, mas que são rotineiros e demandados pelo público nas produções atuais: o amor e a vida noturna/festa ${ }^{12}$. Esses temas são hoje obrigatórios na cultura pop. Dessa forma, os produtores culturais aqui em questão se adaptam a demandas bastante específicas do campo da produção de cultura em massa (cantam sobre o amor e a festa), mas apresentam a sua especificidade ao acabar com a imagem do homem.

Para entender como acontece essa união, passaremos pelos quatro álbuns de estúdio e por dois videoclipes (Robot Rock e Prime time of your life) que trazem uma proposta artístico-estética que caracteriza a banda. Embora clipes e músicas sejam linguagens diferentes, eles compõem uma identidade estética para a banda.

DISCOGRAFIA

O Daft Punk tem quatro álbuns de estúdio: Homework (1997), Discovery (2001), Human after all (2005) e Random Access memories (2013). O prestígio artístico do Daft Punk já é alcançado com o álbum de 1997, tendo dois videoclipes dirigidos por diretores aclamados: Spike Jonze dirigiu Da funk e Michel Gondry dirigiu Around the

\footnotetext{
${ }^{11}$ Em Ode triunfal (1914), Álvaro de Campos - pseudônimo de Fernando Pessoa - expressa seu desejo de união carnal com a máquina:

Eu podia morrer triturado por um motor Com o sentimento de deliciosa entrega duma mulher possuída. Atirem-me para dentro das fornalhas! Metam-me debaixo dos comboios! Espanquem-me a bordo de navios! Masoquismo através de maquinismos! Sadismo de não sei quê moderno e eu e barulho!

${ }^{12} \mathrm{O}$ filósofo e crítico de arte Michel Gaillot, para dizer que as raves são um "laboratório artístico do presente", traz três aspectos fundamentais do techno: 1. é essenciamente festivo, 2. não há posicionamento político, 3. está relacionado com a tecnologia contemporânea (Apud SMITH, 2004, p. 737).
} 
world. Por terem sido criados personalidades conhecidas por seus vídeos e filmes, esses dois primeiros clipes da banda apresentam características autorais de seus diretores. A marca registrada do Daft Punk - a aparição em shows e em público caracterizados de robôs - surgiria com força apenas posteriormente.

Cada álbum apresenta um conceito diferente: Homework pode ser entendido como uma mistura de techno e acid house; Discovery vai pela linha do synthpop; Human after all é totalmente diferente dos dois primeiros, misturando eletrônico com rock; e Random access memories também difere totalmente dos anteriores sendo um retorno à disco music. Ou seja, por mais que a banda diga que espera que seja apreciada pela música que produz, é muito pouco provável que um grande número de pessoas possa ser apreciadora igualmente de sinthpop, rock e disco. Em realidade, fãs da banda o são de fato basicamente pela aura do Daft Punk, pois as mudanças tão drásticas de gênero não poderiam, unicamente pelo aspecto musical, manter os seus apreciadores ${ }^{13}$.

O primeiro álbum, Homework, apresenta faixas com vozes humanas, iniciando-se pela primeira. Entretanto, a utilização que a banda faz, nesse momento, da voz humana é apenas uma espécie de "instrumentalização" da voz, que é o resultado da mistura de certas sílabas, sonoras o suficiente, com determinado timbre, que faz com que ela se misture organicamente com os outros instrumentos. Palavras como "com'on", "everybody", "dance" ou "oh yeah" são exemplos clássicos desse efeito. A primeira faixa de Homework, intitulada Daftendirekt, trata exatamente desse efeito: uma frase "Dafunk back to the punk come on" - que é repetida inúmeras vezes devido ao efeito do tipo de voz usado com as sílabas pronunciadas. Esvaziada de valor semântico, a frase apenas vale pela sua carga sonora. Chamaremos a essa técnica - que se assemelha à técnica de voz empregada pelos futuristas - de "voz silábica".

Ao contrário do rap, que requer a palavra, "o techno rejeita lirismo e narrativa, e confia quase exclusivamente na atmosfera ou nas batidas por minuto para o seu efeito" (Smith, 2004, p. 734). Segundo Smith, o uso dos vocais no techno é geralmente fonético e estético, não semântico; é mais um instrumento musical do que um canal de mensagem - não há mensagem, afinal, os vocais estão descontextualizados. A segunda faixa é uma espécie de imitação de vinheta de rádio e, portanto, efeito de uma metalinguagem em que se pressupõe que os artistas estão, ainda, por detrás do que é exposto. A terceira faixa, Revolution 909, segue a mesma ideia (um efeito de

\footnotetext{
${ }^{13}$ Pode-se contra-argumentar dizendo que bandas mudam de estilo sem, no entanto, perder os fãs que possuem. Contudo, quando o fazem, em geral permanecem sob uma mesma rubrica maior. O Ministry, já citado neste trabalho, mudou bastante, indo do synthpop ao metal, sempre misturando com eletrônico. Mas o Ministry não deixou de fazer algum tipo de rock e, por isso, os fãs permaneceram. Um outro cenário seria se a banda tivesse mudada do synthpop para a salsa, por exemplo. Aí os fãs seguramente deixariam de segui-la. O mesmo ocorreria se fossem do synthpop para a disco music. Existem socialmente algumas fronteiras dentro das quais um grupo de pessoas se reconhece musicalmente e em que uma banda pode fazer experimentações (mesmo dentro do rock, uma banda precisa cuidar quando muda de estilo se quiser manter seu público, pois dois estilos podem ser totalmente incompatíveis: por exemplo, uma banda de heavy metal que comece a fazer grunge, ou o oposto, uma banda grunge que passe para o heavy metal, muito provavelmente perderá o seu público e não conseguirá o apoio do estilo de música no qual está entrando). Curiosamente, o Daft Punk operou uma dessas essas mudanças drásticas de estilo, passou do rock para a disco music, sem grandes inovações em nenhum deles. O prestígio do qual a banda desfruta está em outro lugar e a sua manutenção depende de outros fatores.
} 
metalinguagem em que a música em si está submetida à história contada) e também apresenta vozes humanas. Contudo, elas apenas simbolizam os espectadores de um show que se dá em espaço público: seria o fundo musical de um pretenso conflito entre a polícia e o que quer que esteja tocando - surge um som de alto-falante com alguém dizendo "Stop the music and go home" em meio a outras conversas. Da funk (faixa 4), Phoenix (faixa 5) e Fresh (faixa 6) são uma sequência que não apresenta letra nem vozes. Em seguida entra Around the world (faixa 7), que tem letra e traz o título da faixa repetido por uma voz mecânica. Rollin' \& scratchin' (faixa 8) é a mais mecanizada de todo o álbum, pois não apresenta nenhuma tonalidade: é música totalmente construída com ruídos de samplers. A grande exceção desse álbum é a próxima, Teachers (faixa 9), uma espécie de homenagem da dupla aos produtores culturais que admiram: se trata de um lista bastante grande de nomes - na sua maioria, DJs - que é dita por duas vozes mecanizadas: uma grave e outra aguda. Entretanto, presumem-se nessa faixa ao menos dois elementos humanos: admiração/afeto aos "teachers"; pois as vozes, apesar de mecanizadas, podem, a alguns ouvidos, soarem como vozes humanas com algum efeito. High fidelity (faixa 10) e Oh yeah (faixa 11) são os casos em que o efeito de voz silábica fica mais evidente. Interpondo-se a elas, há a instrumental Rock n' roll (faixa 11). O álbum termina com as instrumentais Burnin' (faixa 13), Indo silver club (faixa 14), Alive (faixa 15) e uma espécie de "citação" da quarta faixa que eles intitularam Funk ad (faixa 16).

O álbum Discovery, de 2001, se inicia com One more time, a faixa talvez de maior sucesso do duo e, curiosamente, uma das faixas em que a voz mecanizada ainda tem muito de humano: trata-se de uma música tonal, melodiosa e que fala sobre celebração, ou seja, a festa. A terceira faixa traz uma das letras mais extensas da banda e fala sobre amor. O sentimento prossegue, embora seja cantado por robôs: quem canta o amor é uma voz robótica e a música se chama Digital love. Também a faixa nove - Something about us - fala sobre amor e, além disso, ao contrário de Digital love, traz uma voz menos robotizada - trata-se da grande exceção desse álbum e da banda, conforme se explicará.

Harder, better, faster, stronger (faixa 4), Crescendolls (faixa 5), Superheroes (faixa 7), High life (faixa 8) trazem voz - voz silábica. Aerodynamics (faixa 2), Nightvision (faixa 6), Voyager (faixa 10), Veridis quo (faixa 11), Short circuit (faixa 12) são instrumentais.

Sobre as faixas com vozes não robotizadas: One more time (faixa 1) e Too long (faixa 14) foram cantadas por Anthony Moore, e Face to face (faixa 13) foi cantada por Todd Edwards. Ou seja, das quatro músicas cantadas por humanos, apenas uma (Something about us) é cantada por um membro da banda, e não por um convidado. Tudo indica que é Thomas Bangalter quem canta. Este recurso de não criar uma identidade vocal para a banda é o elemento principal que possibilita alguma impessoalidade para o duo, o que é uma característica do techno.

O álbum de 2005, Human after all, talvez seja o de título mais contraditório à fantasia mecanicista da banda - e também provavelmente o mais repetitivo de toda a história da música, impressão compartilhada por críticos da banda. Esse álbum é uma mistura de eletrônico com rock e, junto com este último, traz toda a influência do 
universo do rock, o que explica uma pretensa subversão do disco, que tem faixas chamadas The brainwasher ou Television rules the nation, as quais podem soar como músicas contestadoras, mas que, em realidade, apenas fazem referência às temáticas classicamente tratadas pelo rock. Inicia-se com a faixa que dá título ao álbum. A letra é basicamente "We are human, after all. That's uncommon, after all" e é cantada por uma voz totalmente robotizada. O paradoxo aqui é evidente: as frases que celebram o humano são veiculadas por vozes mecânicas. The prime time of your life (faixa 2) é a repetição do título por voz robótica com outras poucas palavras intercaladas entre as repetições. Em Robot rock (faixa 3), Steam machine (faixa 4), The brainwasher (faixa 6), Television rules the nation (faixa 8) e Emotion (faixa 10) há uma voz mecânica repetindo os respectivos títulos da músicas ${ }^{14}$. Make love (faixa 5) é instrumental e $O n$ off (faixa 7) se trata de outra espécie de citação. Technologic (faixa 9) é uma sequência de verbos - ditos por uma voz infantilizada - que dizem respeito ao tema do consumismo, com um refrão que é a repetição do nome da música, ditos pela mesma voz infantilizada. Pode-se dizer que essa listagem extensa e repetida rapidamente também cria um efeito semelhante a da voz silábica. Desse álbum chama muito a atenção a primeira - Human after all - e a última faixa - Emotion: ambas tentam fazer referência ao humano (na primeira, efetivamente dizendo que são humanos e, na última, tendo a palavra "emotion" repetida 77 vezes). Sintomaticamente, o álbum abre e se encerra com faixas que enunciam - por meio de voz robotizada, ressaltemos - a presença do humano, dentro desse álbum em que a mecanização e a repetição são elementos evidentes. É como se todo o conteúdo do álbum estivesse circunstrito por esses dois limites - o humano e o emocial. Portanto, mesmo tendo o tema da máquina como formador da identidade da banda, o duo ainda usa os temas requeridos pela indústria cultural para a obtenção do sucesso: o sentimento, o amor e a festa como temas preferivelmente tratados - embora "tratados por robôs".

Se Human after all é contraditório no título, o álbum de 2013, Random access memories, é contraditório sonoramente: é um retorno à disco music, portanto, os instrumentos são ou parecem ser tocados por humanos. Contudo, quatro músicas são cantadas por vozes robóticas: Give life back to music (faixa 1), The game of love (faixa 2), Within (faixa 4), Instant crush (faixa 5 - que é cantada por Julian Casablancas) e Beyond (faixa 9). Outras três são instrumentais: Giorgio by moroder $^{15}$ (faixa 3), Motherboard (faixa 10) e Contact (faixa 13). Touch (faixa 7) tem uma parte também com voz humana cantada por Paul Williams que se coloca diante de outras vozes mecânicas durante seus 8 minutos. As faixas totalmente com vozes humanas são quatro: Lose yourself to dance (faixa 6) e Get lucky (faixa 8) cantadas por Pharrell Williams, Fragments of time (faixa 11) cantada por Todd Edwards, e Doin' it right (faixa 12) cantada por Noah Lennox.

\footnotetext{
${ }^{14}$ Há uma pequena mudança na música The brainwasher, música na qual o que é repetido é "I am the brainwasher".

${ }^{15}$ Aparece a voz do próprio Giordio Moroder, entretanto, a música não deixa de ser instrumental, pois a voz apenas desenvolve uma narrativa sem se integrar rítmica ou tonalmente à música (ou seja, a voz não canta).
} 
Nos seus quatro álbuns de estúdio, o Daft Punk gravou 53 faixas. Dessas, 4 faixas de Discovery e 4 de Random access memories têm vozes não robotizadas, somando 8. Dessas 8, apenas uma traz a voz de um dos componentes da banda: Something about us. Sendo apenas uma única música com voz humana cantada pela própria banda do total de 53, tem-se reforçada a fantasia mecanicista de que são os robôs que criam e produzem as músicas, convidando humanos para participações especiais quando percebem que a voz humana é a melhor escolha.

\section{DOIS VÍDEOS}

Os vídeos de Robot rock e Prime time of your life chamam a atenção. Ambos se iniciam com os dizerem "Special presentation"16. Prime time of your life mostra uma garota dentro de um quarto, primeiramente passando por canais de televisão: todos os humanos são mostrados como esqueletos. Em seguida, mostra a estante com fotos: a única humana é ela, os seus parentes são também caveiras e, ao final do vídeo, ela se desfaz da própria carne com uma lâmina e acaba no chão do banheiro, sendo socorrida por outros dois humanos que, presume-se, talvez sejam seus pais. Logo, a morte é um tema tratado pela banda: a morte do humano, é claro; a máquina segue.

O clipe de Robot rock chama a atenção por ser o vídeo em que a fantasia aqui descrita é potencializada: trata-se de dois robôs tocando; um toca uma guitarra dupla e o outro toca a bateria. É uma espécie de show, contudo, na plateia não há espectadores. Ou seja: é um show de máquinas para ninguém. A isso, somam-se características do rock do século XX: uma imagem que parece ter sido tirada de um VHS, uma postura tipicamente do rock (a movimentação do guitarrista) e a utilização de uma guitarra dupla, uma com 6 cordas e outra com 12. Convém ressaltar que tudo o que vem do som de uma pretensa guitarra na música é obtido pelo chamado powerchord ou bichord: tipo de acorde conseguido com duas cordas. A música possui apenas um acorde, com uma pequena variação que pode ser feita nas mesmas cordas. Logo, para tocá-la na guitarra, seriam necessárias apenas duas cordas, entretanto, um dos robôs tem 18 cordas em mãos ${ }^{17}$. Sendo uma música que da guitarra se exija apenas powerchords, a presença da guitarra é meramente cenográfica, como um clichê imagético que remete ao mundo do rock.

No momento em que a voz robótica, junto com a guitarra, canta "Rock, robot rock", focaliza-se o robô que toca guitarra, como se ele fosse o responsável pelo que está sendo cantado. A forma como ele move a cabeça e se move em direção à câmera se assemelha bastante à postura de Kurt Cobain na terceira estrofe do videoclipe de Smells like teen spirit - imagem que se tornou canônica na história do rock. Portanto, embora as referências do rock também sejam as mais conflituosas do século XX, no vídeo de Robot rock não há conflito algum. Ao contrário disso, há uma letra formalista que não significa nada, em um ambiente livre de tensão - estando ausente inclusive a plateia

\footnotetext{
${ }^{16}$ Além desses dois, o vídeo de Technologic se inicia da mesma forma.

${ }^{17}$ É certo que em determinado momento, o robô guitarrista fantasia usar mais cordas por tocar mais notas, contudo, aquilo não é proveniente do som de guitarra.
} 
humana ou qualquer tipo de plateia. Se Marinetti explicava a necessidade de desprezar a plateia, o Daft Punk a aboliu.

\title{
A UTOPIA DA MÁQUINA NO MOMENTO EM QUE PARECE NÃO HAVER UTOPIA
}

A velocidade do desenvolvimento colossal da força de produção criada pela burguesia já era percebida por Marx e Engels no século XIX - maior do que as forças produtivas de todas as gerações antecedentes reunidas. Nesse momento, a dominação é criticada. Os operários quebram as máquinas. No século XX, a velocidade dos avanços tecnológicos segue; entretanto, a possibilidade de usufruir deles se estende e, em grande medida, se democratiza. Nesse momento, a dominação é naturalizada. Marcuse, nos anos 1960, era uma das vozes a questionar a positividade do avanço tecnológico ${ }^{18}$. Devido à naturalização da maquinaria na vida social, que facilita o cotidiano, essas críticas foram e são etiquetadas como retrógradas. Já não espanta mais que alguém cante o louvor à máquina, por isso, a violência do futurismo já não é necessária para trazer essa ideia à arte.

Tais mudanças na vida social geraram algumas mudanças também na subjetividade e no simbolismo: o comportamento regido por gráficos, tabelas e análises de estratégias para melhor rendimento tem o seu impacto nas dimensões fora da esfera da produção.

\begin{abstract}
Um homem, que viaje de carro a um lugar distante, escolhe a rota de sua viagem num guia de estradas. Cidades, lagos e montanhas aparecem como obstáculos a serem ultrapassados. O campo é delineado e organizado pela estrada: o que se encontra no percurso é um subproduto ou anexo da estrada. Vários sinais e placas dizem ao viajante o que fazer e pensar. Espaços convenientes para estacionar foram construídos onde as mais amplas e surpreendentes vistas se desenrolam. Painéis gigantes lhe dizem onde parar e encontrar a pausa revigorante. A rota é feita para o benefício, segurança e conforto do homem. E a obediência às instruções representa o único meio de se obter resultados desejados (MARCUSE, 1998, p. 79).
\end{abstract}

De Marcuse de meados do século XX, passemos para o país considerado historicamente como do futebol arte - o Brasil - que hoje escuta frequentemente ideias como "não há gol feio; feio é não fazer gol". Novamente, a lógica da produtividade. Não só o trabalhador, como também o viajante, o jogador de futebol, o amante também tem a sua produtividade medida por quantidades, medições de intensidade, marcadores

\footnotetext{
${ }^{18}$ Chamemos a atenção à crítica com relação à pesquisa espacial: Marcuse, nesse tempo morando nos Estados Unidos, conta que qualquer um que questione a necessidade da pesquisa espacial - em face de demandas sociais tão mais urgentes - é imediatamente qualificado de retrógrado e inimigo do progresso. Para Marcuse, os defensores dos gastos com programas espaciais - cujos resultados muitas vezes não trazem nenhuma consequência sensível para a melhoria da vida na Terra - se sustentam no discurso predominante da racionalidade técnica, a qual concebe o desenvolvimento da técnica como um fim em si. No caso da pesquisa espacial, qualquer objeção e ordem moral ou ética - por exemplo, de que o dinheiro gasto nisso poderia ser mais bem aplicado em alimento, moradia e saúde para quem precise - é respondida com o discurso da necessidade do progresso tecnológico (Marcuse, 1998).
} 
de produtividade. Há toda uma maquinaria disponível para o bom desempenho e drogas disponíveis para que a baixa performance possa ser medicalizada. A superação do homem passa a ser uma realidade em qualquer aspecto da vida. O ideal vislumbrado é a máquina.

O tópos da máquina-homem - comumente figurado na imagem do robô - não deve ser lido somente como uma especulação científico-filosófica sobre a evolução da técnica e as consequências disso para a humanidade. Além desse caráter especulativo, a figura da máquina propicia uma espécie de aglutinação de significados simbólicos. A máquina, como campo semântico-metafórico, pode abrigar uma série de atributos (como insensibilidade, frieza, objetividade absoluta etc.) que nomeiam simbolicamente males sociais formalmente traduzidos nessa figura distópica: "A máquina é mais do que uma metáfora útil para descrever processos econômicos; ela é a figura do implacavelmente objetivo, referindo-se a tudo de automático, inumano e morto sobre a vida social" (Dienst, 1994, p. 37).

Em seu manifesto, Donna Haraway contesta certos dualismos que persistem na tradição ocidental e seriam responsáveis pela dominação de tudo que se constitui como o outro $^{19}$. Para ela,

\begin{abstract}
A cultura high-tech desafia estes dualismos de formas intrigantes. Não é claro quem constrói e quem é construído na relação entre homem e máquina. Não é claro o que é mente e o que é corpo nas máquinas que suscitam práticas codificadas. [...] Não há nenhuma separação ontológica fundamental no nosso conhecimento formal de máquina e organismo, de técnico e orgânico (HARAWAY, 1991, p. 171).
\end{abstract}

Ora, é exatamente essa interligação entre homem e máquina que gera o fim dos dualismos que o techno apresenta como um dos seus valores: "O próprio anonimato do techno o torna sem classe social, sem raça e sem gênero. Em outras palavras, quebra as polaridades que historicamente nos separam: rico e pobre, negro e branco, masculino e feminino, gay e heterossexual e assim por diante" (SMITH, 2004, p. 734).

Smith aqui se refere ao anonimato criado pela falta de identificações dos DJs, podendo cada um deles ter às vezes dezenas de codinomes. Esses codinomes são qualquer nome desprovido de qualquer atributo social: como mostrado acima, não se sabe de que classe social provêm, qual é a cor e, no caso do Daft Punk, se são homens ou mulheres - já que a máquina é assexuada. Todo conflito de classe, de raça, de gênero se esvai. Daí se tira a conclusão de que a rave é um ritual em que não há conflito, muito provavelmente também devido ao efeito do ecstasy. Curiosamente, isso é considerado uma vantagem da cultura techno: é o momento em que se esquece dos problemas do mundo para, estando o corpo e a mente fundida com a máquina, celebrar o nada. Ou, melhor dizendo, por mais que a celebração seja por meio de música e substâncias alucinógenas, ironicamente o que se celebra é a submissão à racionalidade técnica: é o

\footnotetext{
19 A autora cita alguns desses dualismos: self/other, mind/body, culture/nature, male/female, civilized/primitive, reality/appearance, whole/part, agent/resource, maker/made, active/passive, right/wrong, truth/illusion, total/partial, God/man.
} 
momento de comunhão, mas, nesse caso, de comunhão com a máquina. O Daft Punk eloquentemente sintetiza essa ideia e a potencializa: deixam de lado o homem como se fossem eles, as máquinas, regentes de todo o ritual de celebração da racionalidade que, no início do século XX era a celebração violenta da racionalidade de técnica e de Estado e que, agora, apresenta essa nova forma, uma celebração passiva e dócil dessa racionalidade tecnológica, à qual é "logicamente óbvia" a necessidade de obediência.

\section{LAPSO EPISTEMOLÓGICO}

Finalmente, acaba aqui a tentativa de análise sociocultural e entra mais explicitamente o incômodo de quem resolveu escrever esse texto, a princípio, não por motivos acadêmicos, mas por gostar do tema. Ao contrário da marcha cultural que renega o conflito, a autoria, o sentimento, a festa não institucionalizada, o vazio, existe ainda assim todo um conjunto de pessoas que insiste no contrário, que insiste na bobagem de que o homem é um ser que sente, se emociona, se alegra e se dói. Logo, não se poderia terminar esse texto sem um "viva!": à gravação deliberadamente ruim do Guided by Voices até 1996; à intransigência do Arcade Fire em tratar de temas que são trabalhados desde o romantismo e que, no palco, por meio de performances experimentais, tentam demonstrar em gestos, agressões e posturas (que não têm importância nenhuma para o som produzido) toda a gama de emoções que uma pessoa pode ter; ao Beirut pelos belos vídeos que mostram o trabalho artesanal que é fazer música; ao Tame Impala que usa diversos recursos tecnológicos sobre os instrumentos e a voz como forma de exacerbar a experiência do sonho; a todo o punk, que nos lembra que não é apenas o conflito interno de cada um que pode ser cantado, mas também o conflito proveniente de uma sociedade organizada hierarquicamente; ao Killing Joke que tenta desvendar os mistérios do universo e exorcizar-se; ao Tom Zé, que, apesar de todas as experimentações, sabe que é necessário deixar de lado tudo o que aprendeu em uma faculdade de música, para fazer música. A todos eles gostaríamos de dedicar esse texto.

\section{REFERÊNCIAS}

ADORNO, Theodor. Prismas: crítica cultural e sociedade. São Paulo: Ática, 1998.

ADORNO, Theodor. "The Curves of the needle". In.: October, Vol. 55 (Winter, 1990), pp. 48-55 (http://www.jstor.org/stable/778935 acessado em agosto 2013).

AUNER, Joseph. “'Sing it for me': posthuman ventriloquism in recent popular music". In.: Journal of the Royal Musical Association, vol. 128, $\mathrm{n}^{\mathrm{o}}$ 1, 2003, pp. 98-122.

BENJAMIN, Walter. Magia e técnica, arte e política: ensaios sobre literatura e história da cultura. São Paulo, Brasiliense, 1994 (Obras escolhidas; vol. 1).

Charles Baudelaire: um lírico no auge do capitalismo. São Paulo: Brasiliense, 1989.

BERNARDINI, Aurora Fornoni. O futurismo italiano. São Paulo: Perspectiva, 1980.

BOURDIEU, Pierre. As regras da arte: gênese e estrutura do campo literário. São Paulo: Companhia das Letras, 1996.

DIENST, Richard. Still life in real time: theory after television. Durham \& London: Duke University Press, 1994. 
FELINTO, Erick. A Religião das Máquinas: ensaios sobre o Imaginário da Cibercultura. Porto Alegre: Sulina, 2005.

GOLDBERG, RoseLee. A arte da performance: do futurismo ao presente. São Paulo: Martins Fontes, 2006.

HARAWAY, Donna. A Cyborg manifesto: science, technology, and socialist-feminism in the late twentieth century. In.: Simians, cyborgs and women: the reinvention of nature. New York: Routledge, 1991.

HORKHEIMER, Max. Eclipse da razão. São Paulo, Centauro, 2000.

HUMPHREYS, Richard. Futurismo. São Paulo: Cosac \& Naify, 2001.

MIGLIACCIO, Luciano. As vanguardas da $1^{\circ}$ metade do século XX / A arte depois da $2^{\circ}$ guerra mundial. São Paulo, TV Cultura / CPFL, 2005 (documentário).

PERLOFF, Marjorie. The futurism moment: avant-guerre, and the language of rupture. Chicago: University of Chicago Press, 1986.

SMITH, Nigel. "And the beat goes on: an introduction to French techno culture". In: The French Review, vol. 77, $\mathrm{n}^{\circ} 4$ (Mar., 2004), pp. 730-741 (http://www.jstor.org/stable/25479461 acessado em junho de 2013).

VERTOV, Dziga. "Nós". I.: XAVIER, Ismael (org.) A experiência do cinema. Rio de Janeiro: Graal, 1983.

ZIZEK, Slavoj. On Belief. London/New York: Routledge, 2001.

Recebido em: 24/09/2013. Aprovado em 15/06/2014.

Title: 'Human after all'? Daft punk and the cult of the machine

Author: Marcelo Cizaurre Guirau; Rafael Mantovani

Abstract: Daft Punk is a duo formed in the 1990s and widely recognized in the next decade. They are considered by many as innovator and display themselves a musical experimentation discourse. Their most recent album (Random Access memories), released in 2013, was a public and critical success and was awarded - among four other categories - Best Album of 2013 in the 2014 Grammy Award. What Daft Punk really brings as innovation is the abolition of the human figure, which can be accomplished either by having robots rather than humans as frontmen or by using mechanical voices instead of a human one. By abolishing the human figure and fantasizing that the music is being done by machines, the band achieves a definitive representation of the mechanicist dream of the $20^{\text {th }}$ century, announced for the first time by the Futurist school.

Keywords: Techno. Daft Punk. Utopia. Machine. Cyborg. 